\title{
The final stage of human development? Erikson's view of integrity and old age
}

\author{
By CHRIS GILLEARD*
}

\begin{abstract}
This paper considers the significance for ageing studies of Erikson's theory of adult development, particularly his last stage the crisis of 'integrity' versus 'despair'. Because his model assumes a clear pattern of lifelong upward development, culminating with the 'achievement' of integrity and wisdom, it can be seen as helping underpin gerontology's moral imperative to confer meaning and value upon old age. Despite the difficulties in empirically demonstrating the stage-like nature of adult development, and the dubious evidence that integrity is an essential feature of a successful old age, the inherent directionality of Erikson's model supplies ageing with a purposive quality in contradistinction to alternative 'decline' narratives. Rather than continue a potentially fruitless search for proof, it might be better to conceptualise his adult 'stages' of identity, intimacy, generativity and integrity as key narratives running through the development of adult character, articulated, expressed and struggled over in various ways throughout adulthood, including late life.
\end{abstract}

Keywords: Erikson, Integrity, Stages of development.

${ }^{*}$ Chris Gilleard, Ph.D., Hon. Assoc. Professor, Division of Psychiatry, UCL Faculty of Brain Sciences, London, U.K. 
International Journal of Ageing and Later Life

\section{Introduction}

Much credit is due to Erik Erikson in proposing a view of human development that continues throughout the realisable human lifespan (Kivnick \& Wells 2014: 40). Some have claimed that "there has not been a more influential theory of psychosocial development" (Dunkel \& Harbke 2017: 58). Although the idea of the lifelong development of human character goes back thousands of years, appearing and reappearing in a wide range of cultures (Arnett 2017), Erikson's achievement was to formulate a set of principles to account for that development that seemed explicit and testable. His model assumed that human development could be understood as being (1) stage like, with definite transitions from one stage to another (2) epigenetic, in the sense that each stage emerges from, but is not reducible to earlier stages at the same time as being (3) universal in form and sequence (Erikson 1982). In elaborating this model, Erikson drew heavily upon biographical resources, particularly those of major historical figures such as Ghandi and Luther (Erikson 1958, 1969, 1975). His model of psychosocial development has been the subject of much research, conceptual elaboration and radical critiques (Coles 1970; Friedman 1999; Hoare 2002; Newton \& Stewart 2012; Roazen 1980). Perhaps, the most long-lasting value of his work, however, lies in its underlying message, as much moral as it is empirical, that human development extends beyond the mere achievement of adult form and reproductive fitness into old age.

While the trans-species trajectory of the life course can be summarised as one of birth, growth, stability and decay, Erikson's position was that development is evident throughout the course of human life, during periods of both biological growth, stabilisation and decay. This "uplifting" narrative - implying that human beings at every age continue to possess the capacity to grow and to become more thoroughly human during the course of their adult life - has become a central tenet of much contemporary gerontology (Kivnick \& Wells 2014: 48). From such a viewpoint, a wide range of lifespan developmental themes have been proposed from Baltes' model of selective optimisation (Baltes 1997; Baltes \& Baltes 1990) and McAdams' theory of the narrative self (McAdams 2019; McAdams \& McLean 2013) to researchers such as Becca Levy who has challenged the intrinsic decline narratives by which later life is defined as largely 
socio-cultural constructions (Levy 2003). While there is much debate over the limits of human plasticity and the nature and extent of "post-adult" personality change, after Erikson it has become possible to consider the question of continuing adult development open to inquiry.

This paper outlines a critical appraisal of Erikson's final stage of development, the psychosocial crisis of "integrity" and its "basic antipathy," despair (Erikson 1984: 156). It does so for several reasons. In the first place, his model has acquired an almost totemic status in demonstrating the purposiveness of adult development and the positioning of old age as the culmination of that development. Is this actual or merely aspirational? In the second place, like psychoanalysis, Erikson framed his underlying theory as a science but is propounded more often as a moral framing of life and society. Despite a growing number of measures and methods operationalising integrity, little attempt has been made to either analyse their component parts, integrate the differing findings or critique their methodologies. Unsurprisingly, the findings lack consistency.

As a number of authors have noted, most Eriksonian empirical research has focused upon the earlier psychosocial crises of adulthood, identity (vs. identity confusion), intimacy (vs. isolation) and of generativity (vs. stagnation) with much less investigation or further conceptualisation of his proposed final stage (James \& Zarret 2006: 61; Newton \& Stewart 2012: 220; Torges et al. 2008: 1005; Westerhof et al. 2017: 400). When Erikson first conceived his life cycle model of human development in his book, "Childhood and Society" (Erikson 1963), old age and retirement played a relatively small part in adult lives (Winter et al. 2006: 108). In subsequent decades, old age has become a larger and more varied cultural economic and social space as the number of people living through old age has grown remarkably (Cauley 2012; Rowland 2009). How resilient has Erikson's model of this final stage proved in the face of over half a century of cultural and social change? Over the course of a half century of writing, did Erikson himself alter, modify or reject this framing of adulthood and later life? Might its central position be more a function of its totemic value to ageing studies, in rejecting bio-gerontology's "decline narratives" (Gullette 2011) than its status as an empirically supported index of later life development?

Exploring the empirical evidence and theoretical coherence of "integrity" as a "final" phase or stage in human development confronts one of 
International Journal of Ageing and Later Life

the fundamental tenets of gerontology - that lives lived through old age realise aspects of human character and demonstrate human virtues that reflect genuine growth that "fulfils...the promises of childhood" (Erikson 1984: 156). Evidence supporting the "full" emergence of integrity as a positive virtue in later life could provide a strong counter-weight to the view that the psychosocial study of ageing and old age involves little more than the investigation of mental and physical decline and attempts at coping with and adapting to those changes. Although not themselves unworthy topics, the value of these latter endeavours lies largely in their negatives, offering little solace and limited resources to combat nature's iron laws. The need is considerable within the field of psychosocial gerontology for there to be a distinct, positive value attached to old age, what might be thought its moral imperative, to make of old age as something more than mere chronological achievement. While bio-gerontology can be said to have a value in itself, without necessarily having to value old age, its non-biological disciplines (the human, psychological and social sciences) stand in more need of sustaining interest and enthusiasm in what otherwise might easily become another "dismal science." Erikson's model provides that.

This paper aims first, to outline the Erikson's formulation of (and his own evolving views on) the psychosocial crisis of later life as the achievement of integrity and others' interpretations of this construct, then to review the existing research on integrity and its operational elaborations and finally to re-consider retaining, revising or rejecting the "stage-like" status of integrity versus despair as the culminating struggle of adult development. In so doing, two other, secondary aims are intended. The first is to promote the view that character although largely eschewed in contemporary studies of "personality and individual differences" represents an important dimension of psychological functioning, on a par with, if not superior to the maintenance of function, fitness and well-being throughout adult life. The second is to support the potential relevance of integrity (and indeed all the other "staged" achievements of adult development delineated by Erikson) in reframing policy towards later life and the scope for society and its institutions to foster the development of integrity, alongside identity, intimacy and generativity as outcomes that are no less important as "health" and "happiness." 


\section{What Did Erikson Mean By "Integrity"?}

When Erikson introduced his stage model of human development, he was concerned with childhood and the broader issue of identity holding the book together (Friedman 1999: 234). At that stage, Erikson had planned a "seven stages of man" model, moving directly from identity and intimacy to old age. It was his wife, Joan, who suggested including the stage of generativity, in partial recognition of their own actuality as parents. Though neither had at this point in their lives experienced old age, it seemed the inevitable final chapter. Still, his formulation of what became the eighth and last stage, the crisis of "integrity vs. despair" was relatively brief, outlined when "we had no intention of (or capacity for) imagining ourselves as really old" and framed around an imagery of "elders" whose long survival conferred a special obligation to display their dignity to the world (Erikson 1982: 52). Erikson's model of psychosocial development was first expounded in his book, Childhood $\mathcal{E}$ Society, and has been repeated ritually and repetitiously by him, throughout his career (Erikson 1984: 157).

He divided the life span (or life cycle) into eight stages, with four developmental stages leading towards adulthood, and four involved in becoming ever more fully adult (Erikson 1963). Each stage is characterised by a core psychosocial conflict between a syntonic and its opposing, dystonic quality or trait, the resolution of which provides the platform for further development and the acquisition of a particular virtue or characterological strength. In old age, the crisis is between the integrity and despair, the resolution of which sees emerging the virtue of wisdom crowning the end of life. Without the conflict between the syntonic and dystonic traits, Erikson would later insist, the basic characterological strength would not emerge. Nor would it, he added, without a resolution that left the syntonic element dominant (Erikson 1984: 159). The framework of his stage model, he described as "epigenetic," in the sense that while each stage has its critical moment of "full ascendance," this will be most effectively realised by "the proper development in the proper sequence" of all the other stages (Erikson 1982: 29).

According to a later commentator, the broader division between pre- and post-adulthood stages can be seen as a sort of repetition 
International Journal of Ageing and Later Life

- moving "from basic trust to identity, and again from identity to integrity" (Logan 1986: 125). Although, for the purpose of this paper, I will ignore the earlier "cycle," Logan's point is worth retaining. He sees Erikson's model reflecting, not just the continuation of development in adulthood, but within that development envisaging elements of earlier development re-emerging, albeit in different circumstances. In this sense, Erikson is reiterating a point made originally by Freud, that there exists a "compulsion to repeat" in most adults' psychic life, psychological issues, conflicts and developments that had arisen earlier (Freud 1989: 132, 2006: 164). Erikson re-framed this through the principle of "epigenetic recapitulation on a higher developmental level" (Erikson 1982: 40). Logan's general point is that each stage of adult development can also be seen containing within it, elements of all earlier "pre-adult" stages. The important proviso that Logan makes however is that the later stages not only repeat but also improve on the qualities initially established. So, he suggests "the stage of integrity represents the highest form of the themes central to basic trust and identity - a sense of wholeness and self-worth, and a sense of place in a larger scheme of things" (Logan 1986: 129). This point of later stages incorporating and building on earlier developmental stages does unfortunately make attempts to operationalise and test Erikson's model of psychosocial development, particularly problematic for both biographical and psychometric approaches.

Erikson's own later life leads him to row back a little from his earlier formulation of integrity as the final fulfilment of all the earlier stages. As Hoare has noted, in midlife, Erikson had "projected forward his assumptions about the fruits waiting at the end of a long, productive, engaged life" (Hoare 2002: 185). In his late seventies and early eighties, he considered these terms - integrity and wisdom - "somewhat grandiose" and wondered whether these expectations still hold now that "old age is represented by a fast increasing ...group of mere long-lived 'elderlies'" (Erikson 1984: 160). He was already qualifying the last stage as befitting a bracketed "pre-senile" old age, as if intimations of another old age seemed unable to bear the weight of wisdom (Erikson 1982: 54). Throughout his seventies, Erikson considered himself still in the "generative" stage of life (Hall 1983: 24) but leaving that decade behind, his conviction in the virtue awaiting old age had somewhat weakened. 
By the time his "last" book was written, focusing entirely upon the last stage of old age, he was scarcely the author of his own writing. His "intellectual and physical vitality had ebbed"; he was no longer in a position to revise and re-write the "final statement" he had striven for in The Life Cycle Completed. Vital Involvement in Old Age (Erikson et al. 1986) was, as Friedman bluntly noted "a Kivnick production...heavily influenced by Joan," with Erikson's name added "to assure a wider readership" (Friedman 1999: 461-462). In this book, wisdom was described as merely "conveying the integrity of experience in spite of the decline of bodily and mental functions" (Erikson et al. 1986: 38). A general sense is conveyed of "elders" "feeling retired by society, unneeded and unproductive" forming a "large 'functionless' segment of the population" likely to prove catastrophic "for any society" (Erikson \& Kivnick 1986: 294-295).

Erikson clearly was not content with his own final formulations, expressed in the Life Cycle Completed, but it is to others, rather than to this "unauthored" last book that we must turn for further theoretical elaboration of this final struggle between "integrity" and "despair."1 Logan's paper, noted earlier, represents one of the first "post-Eriksonian" reformulations. In his paper, Logan framed "integrity" the last of Erikson's three "core stages" that emphasise the sense of continuity between the individual and his or her place in history as well as his or her place within society. While the first stage of basic trust establishes the infant's sense of both being in the world and being in society (primarily through its attachment to its caregiver[s]), identity provides the pivot between a personal and a social identity - belonging both to oneself, to one's species and to one's society. Integrity is the third core stage, accepting one's life as one's own at the same time as accepting it as one amongst others, as part of society and as part of humanity itself. What Erikson referred

\footnotetext{
${ }^{1}$ The status of "Vital Involvement" is problematic for Erikson scholars, in a way his earlier books were not. While they often elicited severe criticism, the critics were critics of Erikson, the author and agent of his ideas. With Vital Involvement, it is doubtful if this constitutes a development in Erikson's thinking (Friedman describes it as "a rather flat, concrete and linear recapitulation of his life cycle model," Friedman 1999: 462). For this reason, Erikson's Life Cycle Completed will be treated here as his last book, but taking account of his wife's later extension and revision of it (Erikson 1997).
} 
International Journal of Ageing and Later Life

to as the "sense of coherence and wholeness" (Erikson 1982: 65) applies equally to the individual, his or her species being and his or her social being.

Hearn et al., in particular, indicated how the "sense of integration is both intra- and interpersonal" (Hearn et al. 2012). The perceived integrity of one's own life is viewed at this stage, not in splendid biographical isolation but in explicit relation to other lives - imagined broadly as partaking in and serving as a representative of what it is to be "human" and more particularly as what is consonant "with tales of one's cultural group" (Hearn et al. 2012: 2). Such sentiments reflect Erikson's view that integrity encompassed in its "radius of significant relations" all mankind (sic, Erikson 1982: 22). This notion of fusing personal and interpersonal wholeness, of a long life joining all other lives was of course central to Erikson's earlier writings. Subsequently he became disenchanted when applying such features of his earlier version of "elders" to his own peer group of "elderlies," for whom these designations of integrity and wisdom seemed now, in retrospect, "somewhat grandiose" (Erikson 1984: 160). But, by framing his developmental model as one of upward movement - of growing wisdom, reaching integrity - a peak had been reached. His wife's suggestion of yet another ninth stage, also proposed a reversal, a decline even, when the dominance of the syntonic element supporting the "growth and expansion" is reversed and the dystonic acquires "prominence and potency" (Erikson 1997: 106).

With few exceptions, however, most subsequent work on integrity has focused not upon theoretical development but on empirical examination of Erikson's model. Still in the course of what might be termed the "operationalisation" of integrity, some of these studies have sought to redefine or define more clearly what constitutes the "core" of integrity, what constitutes its dystonic opposite, despair and how these concepts relate to other factors and features of personality, adjustment and mental health. Other studies have focused upon research methodologies to elucidate the relationship between all eight stages; how each stage might be distinguished from the other stages, while at the same time demonstrating a common cumulative source of psychosocial development (or character development) over the whole life course. 


\section{The Operationalisation of Integrity}

At the same time as considering integrity a quality of both intra-personal and interpersonal relations necessarily dominant in the achievement of wisdom, it is important, as Erikson himself stressed in relation to each of his "stages," to understand their negative aspects - which, in the case of later life, is the failure to achieve any sense of the "completeness" or "wholeness" of one's life, and the despair that arises from the "disappointments, failures and missed chances in life" (Hearn et al. 2012: 2). Hence, several writers have stressed that integrity should not be assessed uni-dimensionally or as the product of a uni-dimensional process that is more or less realised by the individual, but as a duality with one set of processes fostering integrity, operating alongside its opposite - the processes that are represented by and realised in despair, both necessary components in realising wisdom as the basic strength of later life (Westerhof et al. 2017: 400). Several early studies adopted the strategy of using a single measure of "integrity" to place individuals along a dimension of being more or less "integrated" (e.g. Ryff \& Heincke 1983). Others adopted measures designed to assign individuals to one of several possible "integrity" statuses, basing their assessment upon a combination of responses to issues covered through semi-structured interviews (e.g. Hearn et al. 2012; Walaskey Whitbourne \& Nehrke 1983/84). Others have continued to use self-report scales, measuring the individual's degree of integrity and his or her degree of despair, such as the Northwestern Ego Integrity Scale (Janis et al. 2011; Kleinj et al. 2016; Westerhof et al. 2017). Still, others have used omnibus psychometric questionnaires designed to assess all the eight "psychosocial development" indicators, such as the Expanded Inventory of Psychosocial Development (Boylin et al. 1976; Tesch 1986), the Inventory of Psychosocial Balance (Domino \& Affonso 1990; Domino \& Hannah 1989), the Measure of Psychosocial Development (Hawley 1988), the Modified Erikson Psychosocial Stage Inventory (Darling-Fisher \& Leidy 1988) and the Psychosocial Inventory of Ego Strengths (Markstrom et al. 1997). ${ }^{2}$

\footnotetext{
${ }^{2}$ This latter scale operationalised Erikson's stages differently from the others, contrasting the basic strengths achieved (for the psychosocial crisis of later life, wisdom) with the basic antipathies arising from the failure to achieve that strength (for the psychosocial crisis of later life, disdain). Unlike the other scales, however, it seems to have been employed almost exclusively with adolescents and college-age students.
} 
International Journal of Ageing and Later Life

Other researchers have eschewed both semi-structured interviews and self-report questionnaires and instead have adopted a life narrative approach. These researchers have either elicited written accounts of people's lives and their paths through life, which are then reviewed and the salient themes in those narratives concerning integrity and despair coded as present or absent (Pals 2006; Torges et al. 2009) or have drawn upon archival material from longitudinal follow-up of a cohort, using a system of coding to highlight themes judged to reflect key aspects of either pole in Erikson's developmental stages (Vaillant 2012; Vaillant \& Milofsky 1980). Despite the open-ended nature of such methods, the resulting grading or scoring of narratives reflects other confounding factors such as the articulateness, fluency and reflexivity that respondents display in their writing, and in their telling of their lives, which risk distorting, or restricting interpretations based upon what might be called "good copy."

Given the large number of "measures" of integrity (in contrast to measures of identity, intimacy and generativity, for example), empirical research on the correlates and consequences of integrity has failed to achieve what might be called a cumulative evidence base, since each measure tends to represent a different approach (interview, Q sort, self-report, etc.) and/or a different conceptualisation. Some measures, for example, have emphasised the aspects of "wisdom," as the virtue that Erikson saw emerging from the development of "integrity," others have emphasised the "acceptance of the past," while still others have focused upon "attitudes to the future." Some have focused upon a measure of integrity as a unipolar characteristic associated with general life satisfaction (Torges et al. 2008), some on separate measures of "integrity" and "despair" (Chan \& Nakamura 2016), while others have calculated a composite "resolution" score, typically obtained by subtracting scores on the negative pole from scores on the positive pole, without framing this balance in terms of the presumed wisdom that is acquired in balancing these qualities "in real life" (Ryff \& Heincke 1983; Tesch 1986). Other researchers have sought to identify "narrative themes" dominating the discourses of later life concerning self-dissatisfaction, resistance, the non-acceptance of ageing, fear of death and coming to terms with or failing to come to terms with oneself, one's past and one's connection or lack of connection with others (Rylands \& Rickwood 2001; Torges et al. 2009). Furthermore, most research has focused upon cross-sectional correlational analysis, which is unable 
to demonstrate the emergence, rise and/or fall in individual characteristics implied by Erikson's model. Even these cross-sectional studies have not always shown the anticipated age differences that might be expected, that is, older people scoring more highly than younger people (Hannah et al. 1996; Ryff \& Heincke 1983; Tesch 1986; Webster 2003).

Very few studies have reported the development of human character from adolescence into old age. Even so, most of the published research has been reasonably positive in identifying some kind of construct called "integrity" and, for those that have used such a separate measure, also of "despair" (Van Hiel \& Vansteenkiste 2009; Westerhof et al. 2017). In a follow-up, a sample of college students from 1969 to 2000/2, Sneed et al. (2006) used the Expanded Inventory of Psychosocial Development to examine the changes in integrity, along with basic trust and ego identity. While basic trust and identity scores increased at each of the four measurement points, patterns of change on the "integrity" scales were non-linear, showing an initial decline followed by a rise which was still lower than the initial scores obtained four decades earlier. The researchers raised the question of whether such changes reflected 'period effects' rather than intra-individual development, indicating the possible rise and then fall in more "individualistic" attitudes before and after the late nineteen eighties (Sneed et al. 2012: 155). Another study employed a self-report measure to assess the "acceptance of the past" as a core component of integrity (Rylands \& Rickwood 2001). The authors found that "not accepting the past" contributed "to the prediction of depression" in a multivariate analysis drawing upon the responses from residents of a retirement village in Canberra, Australia (Rylands \& Rickwood 2001: 85). They argued that the failure to achieve "integrity" (judged by the non-acceptance of the past) "caused" some residents to experience mental health problems, but, of course, in such a cross-sectional study, the direction of causality is impossible to determine.

Similar criticisms can be levelled at other, more sophisticated studies, that have pursued a more or less similar strategy, correlating measures of self-reported "integrity" with mental health - albeit recognising that the two aspects of integrity (the struggle for it and the failure of achievingit) may have different correlates and consequences for mental health (Westerhof et al. 2017). Some support exists for further differentiating ego-integrity as an "achievement" into two distinct components - the development 
International Journal of Ageing and Later Life

of meaningful life purpose and the absence of life disappointment feelings, such that despair may arise from either a felt lack of meaning or a felt sense of regret or both (Chan \& Nakamura 2016: 24).

Even when "integrity" is not measured by a scale but by interview, designed to assess it as a "status" rather than a "score," the observed associations with other "well-being" measures remain problematic when data on all measures are collected at the same time (e.g. Hearn et al. 2012). To give these latter authors credit, they recognise the problems in any attempt at empirically validating Erikson's concepts - whether in terms of its correlation with other measures thought likely to be causal of or consequential to the measure of "integrity" or in terms of the construct validity of the chosen measure itself (Hearn et al. 2012: 18). Studies that have adopted a "developmental" approach to test the Erikson's model by employing both longitudinal and cross-sectional measures to show that "success" in achieving earlier stages of growth (such as identity,intimacy and/or generativity) is predictive of later measures of integrity have been broadly supportive (e.g. James \& Zarrett 2006; Torges et al. 2008). However, this may reflect a common core or general factor of ego development "subsuming Erikson's eight stages of psychosocial development" rather than demonstrating a specifically "epigenetic" relationship between stages (Dunkel \& Harbke 2017: 74).

Problems over measurement reflect issues at the very heart of Eriksonian theory. As Hoare has pointed out, Erikson was uneasy about the reification of his stage theory model and particularly its reduction to empirical measures (Hoare 2013: 51). As a clinician, he framed development as a narrative process - a matter of becoming, not of being - that had its own inherent order, but that was always distinctively realised through individual lives lived in particular places and at particular times. His universal framework provided a hermeneutic framework through which to interrogate people's lives, but he never lost sight of the fact that those lives were always and only ever realised "in synchrony with the current times and with the society of those times" (Hoare 2013: 59). Most empirical research on integrity has focused upon reasonably well-educated late middle-aged and early old-aged persons from Western developed economies. Studies have been conducted in several East Asian developed economies, however, which suggest that although integrity may be expressed in somewhat different domains (e.g. through the peacefulness of 
one's relations with the world and the quality of one's inter-generational relationships), the concept itself seems to possess meaning and relevance in those settings (Chang et al. 2008; Kim et al. 2009; Lim \& Chang 2017). Whether that meaning is capable of an analytic, psychometric delineation however remains dubious.

\section{Critique}

There are limits in how far one can take the existing empirical literature on integrity, just as there are limits in how far one can take Erikson's own writings on this topic. The idea that is central to Erikson's view of integrity in human development is that people can, under some circumstances at least, grow as persons, become wiser, more understanding and feel more at peace with themselves and the world as they grow older. This is arguably an aspiration and a hope, the evidence for which can only be glimpsed in most individual lives even as it may be highlighted in some exceptional "elders" (Erikson 1975). But Erikson at times seems to imply something else - that the whole of life can be seen to lead towards the accumulation of a kind of worldly wisdom - what he calls a grand-generative, or generalised grandparenthood narrative of later life (Erikson 1984: 163). Such a position is essentially an aspiration - a wish that it should be so, a desire that it can be so, and of necessity, an anxiety that it might not be so - rather than a repeatedly verified empirical observation. Taking such an essentially moral stance towards human development is as many have noted a reflection of Erikson's own, benign and somewhat grandfatherly style as a major twentieth century figure of American letters - reflecting perhaps his own desire to be considered a wise and ethical older American - a "sage" for his time (Hoare 2000: 75).

At the same time, the longer he lived, the less it seems he was so sure. As he finally relinquished his "generative" stance, late on in his life, his views became less unequivocally benign, as he felt surrounded not by the elders to which he perhaps aspired but to growing number of elderlies instead. The positive resolution promised for old age was, it seems, slowly being overshadowed (Hoare 2002: 220). Wisdom was no longer the outcome of a long life, but a general feature of adult life; as his wife notes, as life elongates further "the dystonic elements win out" (Erikson 1997: 113). Erikson's moral aspirations were increasingly challenged. So often 
International Journal of Ageing and Later Life

criticised, because they seemed "paternalistic," reflecting a male oriented view of the life course and its directions and because they seem to be embedded in a North American context where marriage adaptation career and the raising of children constitute the basis of "the generative life" (Hoare 2002: 219), towards the end of his life he too seems to have become aware of their "grandiosity" (Erikson 1984). Perhaps he was drawing less on direct experience but on some generic, pre-modern set of ideals of later life, reflecting the equally paternalistic views of older men displaying and dispensing wisdom (Cicero 1923; Plutarch 1936).

While such views were often expressed by pre-modern philosophers, politicians or religious leaders, Erikson started off propounding something similar as a psychologist, a modern man of science. Erikson's framing of his status, not as an artist, a philosopher, politician or writer but as a practitioner of psychology and psychoanalysis echoes Freud's sense of himself as always a scientist. Unsurprising then that this has been a point of reference from which other students of human development and personality have framed their investigations seeking to define his terms operationally in order to render his model as empirically testable. Two themes become interwoven as a result: the first the more specific, that later life is a period marked distinctly by the intra-psychic struggle between integrity and despair; the second the more general, that human or personal development continues through and builds upon each successive stage of life through to and including old age. While it may be possible to demonstrate support for the latter, it may be argued that such development is neither confined to, nor expressed primarily through the achievement of "wisdom" nor realised in the struggle for "integrity" and that, as Erikson seems increasingly to have realised, these are lifelong struggles of adulthood, to be wise, to take responsibility for one's actions and, despite doubts and moments of despair, to seek purpose and meaning in life.

Although it may be the case that change is possible at each stage of life, longitudinal studies of both intellectual abilities and personality traits suggest that their stability increases progressively over time and with increasing age (Briley \& Tucker-Drob 2014, 2015; Fraley \& Roberts 2006). Change does not necessitate development no more than trait stability implies the absence of development. In contrast to studies focusing upon intellectual or personality traits, studies that have attempted 
to measure the trajectory of the proposed stages in Erikson's model of adult development - such as identity, intimacy and generativity - have however produced mixed findings (Beyers \& Seiffge-Krenke 2010; Newton \& Stewart 2012; Schoklitsch \& Baumann 2012; Sneed et al. 2006; Torges et al. 2009). This uncertainty is compounded by Erikson's own insistence of a "lifelong interweaving of items which develop in successive stages... [that is evident] in all previous stages ... and will be revised and renewed in all subsequent stages" (Erikson 2006: 143). Erikson recognises that the themes underlying his stages of development are (1) lifelong issues, present at each stage of life, in some shape or form but (2) which become dominant at particular times in the life course. This means that "scores" can be obtained for the traits characterising each of the eight stages at any point in time, without any requirement that adults' or adolescents' must obtain higher or lower scores dependent upon their age/stage of life. Furthermore, Erikson acknowledged that their expression will also depend upon the social ethos that actualises them and the intergenerational linkages that contextualise them, so that it becomes possible to envisage secular and cultural changes in their expression. ${ }^{3}$

In a sense, Erikson must be right - personal qualities of whatever nature can only be realised in a social setting. Moreover, his choice of themes in adult development - identity, intimacy, generativity and integrity - seems a priori important human qualities for society. It is difficult to imagine a society where adults had no sense of identity, formed no intimate relationships, contributed nothing to future generations and felt no sense of coherence in their lives. By treating these as epigenetic stages in adulthood, however, Erikson implies at the very least that the "earlier" stages are necessary for the "later" stages to mature, while the later stages are not necessary for the earlier stages to become salient: without identity there can be no intimacy; without intimacy there can be no generativity; and without generativity there can be no integrity. In short, while Erikson assumes a "developmental ordering" of adulthood, it is difficult to "prove" or "disprove" such ordering because of the provisos he makes concerning the recapitulation, re-enactment and anticipation of each and

${ }^{3}$ The work of Jean Twenge illustrates the possibility of quite marked period effects on character traits associated with social and cultural, rather than personal change (Twenge 2014). 
International Journal of Ageing and Later Life

every "crisis" across the adult life course (Beyers \& Seiffge-Krenke 2010: 388; Dixon 1998). What is at stake is whether "integrity" is a demonstrable, empirical "proof" of psychosocial development in later life, capable of being distinctly shown by observed cross-sectional or longitudinal observation, or whether it is sufficient to say that it is a valid, measurable concept, dependent upon the psychometric characteristics of whatever scale, rating or features are being used that possess face validity, whose causes consequences and components are largely independent of age and stage of life. Efforts to fully operationalise Erikson's stages and to analytically model their developmental ordering might be not just impractical but unnecessary, should one conclude that their importance and interrelationships lie in their constituting key components of a generic "ego-development" or "maturity" rather than as "emergent properties" only appearing in full form in later life.

\section{Conclusion}

Erikson was aware that the processes that shape individual lives operate through both the biological and the social, even as they are, as individual lives, thoroughly psychological, in the sense of their being acted, experienced and understood by individual persons. Personality development reflects both the biological processes underlying growth, maturity and decay and the social continuities realised through the institutions of society that acknowledge, frame and support the ordering of the life course (Briley \& Tucker-Drob 2014). Time place and circumstance will affect accentuate or attenuate these processes and the strength of such institutional influences, while the narratives by which individual lives are constructed will themselves be constrained by how lives can be told. What Erikson's model of development offers, perhaps, is not so much a kind of hidden truth underlying the path that lives must follow but an aspiration for what a human life can amount to. In that sense, he is as much a moral philosopher as a psychologist, a social commentator as much as a psychoanalyst who bears affinities as much with the pre-modern world as with modern traditions in thinking about the nature of human life.

His theory emphasises development, not differences. It is as strong as his vision, and his vision was clearly affected by the circumstances of his own life, his experiences of the history he lived through and the peoples 
and communities with whom he worked (Douvan 1997; Friedman 2004; Roazen 1980). Thus, his work on identity caught the spirit of the times. Just as identity politics were beginning to emerge, so his writings appeared setting forth the centrality of youth and identity as the platform from which all adult lives are built. The issues that once emerged at this "pivotal" point in development (Logan 1986: 125) never disappear, as identity continues to remain a central issue across all adult lives and arguably within and between nearly all cultures and communities (Arnett 2017; Logan 1986; Marcia 2014). At the same time, old age was not an issue, not for him, not for society, at the time he first articulated his model. The stages of adult development that Erikson outlined in the immediate postwar era are of course salient issues in most adult lives - of achieving, losing and restoring a sense of belonging and closeness, of establishing continuities over time and across the generations and of taking responsibility for one's life. The question is whether Erikson should be given credit primarily for articulating this point so eloquently or for theorising it so well - or both.

Erikson's theory is as much prescriptive as it is descriptive. It offers a narrative ordering of human development, of how to become and how to be an adult. This moral direction makes it significantly different in emphasis from theories of development that focus upon personality traits, personal adjustment or "global" well-being, even if it is thereby rather too accomodationist, individualistic, moralistic and paternalistic (Gilligan 1982; Hoare 2002; Novak 1986; Riley 1978; Roazen 1980). As such it seems doubtful if it can lead to clearly testable science, without losing its inherent narrative flexibility. Its value lies not in representing a "bio-psycho-social" pathway of adult development as the super-structural outcome of some genetic or over socialised programme directing what constitutes a valuable human life, but rather as a hermeneutic, a coherent narrative capable of rendering sensible and understandable those things of which it tells - the narratives of a life. In this sense, it highlights the importance of development as a possibility throughout the adult life arguably a key construct underlying gerontology itself (Kivnick \& Wells 2014), the importance of identity, intimacy, generativity and integrity as the key aspects of adult character and its maturation within an individual life, while offering an essentially narrative approach towards the study of human lives that recognises conflict, struggle and the operation 
International Journal of Ageing and Later Life

of influences operating beyond those of which we are conscious (Hoare 2013).

Rather than insisting upon each of a measurable, stage-like epigenetic emergence of these phenomena within an individual life, it is possible to envisage them as central features whose precise contours vary over time and place. As such, they may emerge and re-emerge at various points in various forms in an individual's life. In that sense, those researchers who have explored the multi-dimensionality of these stages, or statuses, provide a valuable corrective to more uni-directional, uni-dimensional approaches to adult development. What is most important, perhaps, is the acknowledgement that reaching reproductive fitness or biological adulthood is not the end of human development and that longer lives if nothing else may provide wider arenas for the play of such development. But whether later life provides a specific arena that is in some way necessary for the development of certain qualities like "wisdom" seems much more debatable. Even Erikson later in life would acknowledge his earlier over-egging of this virtue, subsequently de-centering its position as the stage-specific outcome of the psychosocial crisis of later life (Hoare 2002: 185).

Accepting that the concerns evident in later life may be evident at earlier stages of adulthood and that many earlier concerns over identity intimacy and generativity may reappear in later life, these core issues in Erikson's theory of adult development remain valuable. Among various options are the recognition that personal development may continue to take place throughout adulthood, that much of that development hinges upon issues of identity, intimacy, generativity and integrity, that these issues address central concerns of growing up, of maturity and that they are sufficiently universal for there to be collective narratives, rituals and structures that make sense of and provide social imaginaries for such achievements (Arnett 2017).

The fact that, of all the stages of life, old age is currently undergoing the most rapid social change with more people living through it in more diverse ways and under more diverse circumstances, suggests that the forms taken by any later life "developmental" processes may be particularly fluid. As such, they deserve equally fluid modes of inquiry. Rather than being constrained by ordering and operationalising Erikson's 
model, or insisting that old age has a distinct or particular meaning or purpose relatively undeveloped and unexpressed earlier in adulthood, the best way of realising his legacy might be to develop a greater diversity in our explorations of adult character. In so doing, we should bear in mind the three dimensions that Hoare felt were all too often missing from research in this area - the unconscious, the existence of negative attributes and the fluidity of society - that Erikson did not (Hoare 2013). This is perhaps as much a moral imperative for ageing studies to embrace as any insistence upon clothing old age with some more singular virtue.

\section{Corresponding Author}

Chris Gilleard, Division of Psychiatry, UCL Faculty of Brain Sciences, Maple House 149 Tottenham Court Road, London, W1T 7NF. Email: c.gilleard@ucl.ac.uk

\section{References}

Arnett, J. J. (2017). Life stage concepts across history and cultures: Proposal for a new field on indigenous life stages. Human Development 59(5): 290-316.

Baltes, P. B. (1997). On the incomplete architecture of human ontogeny: Selection, optimization, and compensation as foundation of developmental theory. American Psychologist 52(4): 366-380.

Baltes, P. B. \& Baltes, M. M. (1990). Psychological perspectives on successful aging: The model of selective optimization with compensation. In P. B. Baltes \& M. M. Baltes (eds.), Successful Aging: Perspectives from the Behavioral Sciences (pp. 1-34). New York: Cambridge University Press.

Beyers, W. \& Seiffge-Krenke, I. (2010). Does identity precede intimacy? Testing Erikson's theory on romantic development in emerging adults of the 21st century. Journal of Adolescent Research 25(3): 387-415.

Boylin, W., Gordon, S. K. \& Nehrke, M. F. (1976). Reminiscing and ego integrity in institutionalized elderly males. The Gerontologist 16(2): $118-124$. 
International Journal of Ageing and Later Life

Briley, D. A. \& Tucker-Drob, E. M. (2014). Genetic and environmental continuity in personality development: A meta-analysis. Psychological Bulletin 140(5): 1303-1331.

Briley, D. A. \& Tucker-Drob, E. M. (2015). Comparing the developmental genetics of cognition and personality over the life span. Journal of Personality 85(1): 51-64.

Cauley, J. A. (2012). The demography of aging. In A. B. Newman \& J. A. Cauley (eds.), The Epidemiology of Aging (pp. 3-14). Dordrecht: Springer.

Chan, T. M. \& Nakamura, J. (2016). A generativity track to life meaning in retirement: Ego-integrity returns on past academic mentoring investments. Work, Aging and Retirement 2(1): 24-37.

Chang, S. O., Kim, J. H., Kong, E. S., Kim, C. G., Ahn, S. Y. \& Cho, N. O. (2008). Exploring ego-integrity in old adults: A Q-methodology study. International Journal of Nursing Studies 45(2): 246-256.

Cicero, M. T. (1923). Essays on Old Age, On Friendship, On Divination. (Trans. W. A. Falconer). Cambridge: Harvard University Press.

Coles, R. (1970). Erik H. Erikson - the Growth of His Work. Souvenir Press. London.

Darling-Fisher, C. S. \& Leidy, N. K. (1988). Measuring Eriksonian development in the adult: The modified Erikson psychosocial stage inventory. Psychological Reports 62(3): 747-758.

Dixon, J. A. (1998). Developmental ordering, scale types, and strong inference. Developmental Psychology 34(1): 131-146.

Domino, G. \& Affonso, D. D. (1990). A personality measure of Erikson's life stages: The Inventory of Psychosocial Balance. Journal of Personality Assessment 54(3-4): 576-588.

Domino, G. \& Hannah, M. T. (1989). Measuring effective functioning in the elderly: An application of Erikson's theory. Journal of Personality Assessment 53(2): 319-328.

Douvan, E. (1997). Erik Erikson: Critical times, critical theory. Child Psychiatry and Human Development 28(1): 15-21.

Dunkel, C. S. \& Harbke, C. (2017). A review of measures of Erikson's stages of psychosocial development: Evidence for a general factor. Journal of Adult Development 24(1): 58-76.

Erikson, E. H. (1958). Young Man Luther: A Study in Psychoanalysis and History. New York: W.W. Norton \& Co. 
Erikson, E. H. (1963). Childhood and Society (2nd ed.) Harmondsworth: Penguin Books.

Erikson, E. H. (1969). Gandhi's Truth: On the Origins of Militant Nonviolence. New York: W.W. Norton \& Co.

Erikson, E. H. (1975). Life History and the Historical Moment: Diverse Presentations. New York: W.W. Norton \& Co.

Erikson, E. H. (1982). The Life Cycle Completed: A Review. New York: W. W. Norton.

Erikson, E. H. (1984). Reflections on the last stage - And the first. The Psychoanalytic Study of the Child 39: 155-165.

Erikson, E. H., Erikson, J. \& Kivnick, H.Q. (1986). Vital Involvement in Old Age. W.W. Norton \& Co., New York.

Erikson, E. H. (2006). On the generational cycle - An address. In G. Junkers (ed.), Is It Too Late? Key Papers on Psychoanalysis and Ageing (pp. 141-159). London: Karnac Books.

Erikson, J. (1997). The ninth stage. In E. H. Erikson \& J. M. Erikson (eds.), The Life Cycle Completed (Extended Version) (pp. 105-114). New York: W. W. Norton.

Fraley, C. \& Roberts, B. W. (2004). Patterns of continuity: A dynamic model for conceptualizing the stability of individual differences in psychological constructs across the life course. Psychological Review 112: 60-74.

Freud, S. (1989). New Introductory Lectures on Psycho-analysis. New York: W.W. Norton.

Freud, S. (2006). Beyond the pleasure principle. In A. Phillips (ed.), The Penguin Freud Reader (pp. 132-195). London: Penguin Books.

Friedman, L. J. (1999). Identity's Architect: A Biography of Erik H. Erikson. London: Free Association Books.

Friedman, L. J. (2004). Erik Erikson on generativity: A biographer's perspective. In E. de St. Aubin, D. P. McAdams \& T.-C. Kim (eds.), The Generative Society: Caring for Future Generations (pp. 257-264). Washington, DC: American Psychological Association.

Gilligan, C. (1982). In A Different Voice. Cambridge, MA: Harvard University Press.

Gullette, M. M. (2011). Agewise: Fighting the new ageism in America. University of Chicago Press, Chicago.

Hall, E. (1983). A conversation with Erik Erikson. Psychology Today 17(6): 22-24. 
International Journal of Ageing and Later Life

Hannah, M. T., Domino, G., Figueredo, A. J. \& Hendrickson, R. (1996). The prediction of ego integrity in older persons. Educational and Psychological Measurement 56(6): 930-950.

Hearn, S., Saulnier, G., Strayer, J., Glenham, M., Koopman, R. \& Marcia, J. E. (2012). Between integrity and despair: Toward construct validation of Erikson's eighth stage. Journal of Adult Development 19(1): 1-20.

Hoare, C. H. (2000). Ethical self, spiritual self: Wisdom and integrity in the writings of Erik H. Erikson. In M. E. Miller \& S. R. Cook-Greuter (eds.), Creativity, Spirituality, and Transcendence: Paths to Integrity and Wisdom in the Mature Self (pp. 75-98). Stamford: Ct. Ablex Publishing.

Hoare, C. H. (2002). Erikson on Development in Adulthood: New Insights from the Unpublished Papers. Oxford: Oxford University Press.

Hoare, C. (2013). Three missing dimensions in contemporary studies of identity: The unconscious, negative attributes, and society. Journal of Theoretical and Philosophical Psychology 33(1): 51-67.

James, J. B. \& Zarrett, N. (2006). Ego integrity in the lives of older women. Journal of Adult Development 13(2): 61-75.

Kim, H. K., Lee, H. J., Ju, Y. J. \& Park, S. M. (2009). Factors influencing the ego integrity of elders living alone. Journal of Korean Gerontological Nursing 11: 204-215.

Kivnick, H. Q. \& Wells, C. K. (2014). Untapped richness in Erik H. Erikson's rootstock. The Gerontologist 54(1): 40-50.

Levy, B. R. (2003). Mind matters: Cognitive and physical effects of aging self-stereotypes. The Journals of Gerontology Series B: Psychological Sciences and Social Sciences 58(4): P203-P211.

Lim, S. Y. \& Chang, S. O. (2018). Nursing home staff members' subjective frames of reference on residents' achievement of ego integrity: AQ-methodology study. Japan Journal of Nursing Science 15(1): 17-30.

Logan, R. D. (1986). A reconceptualization of Erikson's theory: The repetition of existential and instrumental themes. Human Development 29(3): 125-136.

Markstrom, C. A., Sabino, V. M., Turner, B. J. \& Berman, R. C. (1997). The psychosocial inventory of ego strengths: Development and validation of a new Eriksonian measure. Journal of Youth and Adolescence 26(6): 705-732. 
McAdams, D. P. (2019). "First we invented stories, then they changed us": The evolution of narrative identity. Evolutionary Studies in Imaginative Culture 3(1): 1-18.

McAdams, D. P. \& McLean, K. C. (2013). Narrative identity. Current Directions in Psychological Science 22: 233-238.

Newton, N. J. \& Stewart, A. J. (2012). Personality development in adulthood. In S. K. Whitbourne \& M. J. Sliwinski (eds.), The Wiley-Blackwell Handbook of Adulthood and Aging (pp. 209-235). Chichester, UK: Wiley \& Sons.

Novak, M. (1986). Biography after the end of metaphysics: A critique of epigenetic evolution. The International Journal of Aging and Human Development 22(3): 189-204.

Pals, J. L. (2006). Narrative identity processing of difficult life experiences: Pathways of personality development and positive self-transformation in adulthood. Journal of Personality 74(4): 1079-1110.

Plutarch. (1936). Whether an old man should engage in public affairs. In Moralia, vol. X, (pp. 73-153). [trans. H. N. Fowler]. Cambridge, MA: Harvard University Press.

Roazen, P. (1980). Erik H. Erikson's America: The political implications of ego psychology. Journal of the History of the Behavioral Sciences 16(4): 333-341.

Rowland, D. T. (2009). Global population aging: History and prospects. In P. Uhlenberg (ed.), International Handbook of Population Aging (pp. 37-65). Dordrecht: Springer.

Ryff, C. D. \& Heincke, S. G. (1983). Subjective organization of personality in adulthood and aging. Journal of Personality and Social Psychology 44(4): 807-812.

Rylands, K. J. \& Rickwood, D. J. (2001). Ego-integrity versus ego-despair: The effect of "accepting the past" on depression in older women. The International Journal of Aging and Human Development 53(1): 75-89.

Schoklitsch, A. \& Baumann, U. (2012). Generativity and aging: A promising future research topic? Journal of Aging Studies 26(3): 262-272.

Tesch, S. A. (1986). Psychosocial development and subjective well-being in an age cross-section of adults. The International Journal of Aging and Human Development 21(2): 109-120. 
International Journal of Ageing and Later Life

Torges, C. M., Stewart, A. J. \& Duncan, L. E. (2008). Achieving ego integrity: Personality development in late midlife. Journal of Research in Personality 42(4): 1004-1019.

Torges, C. M., Stewart, A. J. \& Duncan, L. E. (2009). Appreciating life's complexities: Assessing narrative ego integrity in late midlife. Journal of Research in Personality 43(1): 66-74.

Twenge, J. M. (2014). Generation Me-Revised and Updated: Why Today's Young Americans Are More Confident, Assertive, Entitled - and More Miserable than Ever Before. New York: Simon and Schuster.

Vaillant, G. (2012). Triumphs of Experience: The Men of the Harvard Grant Study. Cambridge, MA: Harvard University Press.

Vaillant, G. E. \& Milofsky, E. (1980). Natural history of male psychological health: IX. Empirical evidence for Erikson's model of the life cycle. The American Journal of Psychiatry 137: 1348-1359.

Van Hiel, A. \& Vansteenkiste, M. (2009). Ambitions fulfilled? The effects of intrinsic and extrinsic goal attainment on older adults' ego-integrity and death attitudes. The International Journal of Aging and Human Development 68(1): 27-51.

Walaskay, M., Whitbourne, S. \& Nehrke, M. (1983-1984). Construction and validation of an ego integrity status interview. International Journal of Aging and Human Development 18(1): 61-72.

Webster, J. D. (2003). An exploratory analysis of a self-assessed wisdom scale. Journal of Adult Development 10(1): 13-22.

Westerhof, G. J. Bohlmeijer, E. T. \& McAdams, D. P. (2017). The relation of ego integrity and despair to personality traits and mental health. Journals of Gerontology, Series B Psychological Sciences and Social Sciences 72(3): 400-407.

Winter, D. G., Torges, C. M., Stewart, A. J., Henderson-King, D. \& Henderson-King, E. (2006). Pathways toward the third age: Studying a cohort from the "golden age." Annual Review of Gerontology \& Geriatrics 26: 103-129. 